\title{
La larga crisis terminal del modelo rentista petrolero venezolano y la profunda crisis que actualmente enfrenta el país*
}

\section{RESUMEN}

En este ensayo se busca presentar y explicar la crisis económica y política más grave que vive Venezuela desde las guerras civiles del siglo xix. Explora la crisis política, económica y social en un ciclo de agotamiento de un modelo rentista y una gestión caótica del Estado en un tiempo en la que los sectores populares se encuentran debilitados organizativamente y la oposición política ensaya salidas violentas buscando agudizar un enfrentamiento civil en esta segunda década del siglo xxi. Ensaya varios postulados explicativos sobre la situación en que se encuentran los Movimientos y organizaciones populares ante la crisis.

Palabras Clave: Venezuela; Maduro; Estado; movimientos populares; crisis política.

\section{The long terminal crisis of the Venezuelan oil rentier model and the deep crisis currently facing that country}

\section{ABSTRACT}

This essay seeks to present and explain the most serious economic and political crisis that Venezuela has experienced since civil wars of 19th century. Also, it explores the political, economic and social crisis in a exhaustion cycle of a rentier model with a chaotic management of public administration, at a time when popular sectors are organizationally weakened and political opposition tries violent ways to worsen civil confrontations in this second decade of the 21 st century. Finally, it elaborates several explanatory postulates about the situation of the movements and popular organizations which are facing the crisis.

KeYworDs: Venezuela; Maduro; State; popular movements; political crisis.

\footnotetext{
* Una versión anterior, más reducida de este texto, escrita conjuntamente con Santiago Arconada Rodríguez fue publicada como: «Venezuela: un barril de
} pólvora», Nueva Sociedad, no. 269, Buenos Aires, mayo-junio de 2017. 
E n este texto no voy a intentar siquiera un somero balance del proceso bolivariano con sus muy importantes logros nacionales y regionales y las numerosas contradicciones, errores $y$ limitaciones que han caracterizado a este intento de una radical transformación anticapitalista. Me referiré fundamentalmente a la intensa crisis que actualmente enfrenta el país.

Después de más de una década de profundas transformaciones políticas y sociales, Venezuela está viviendo hoy su crisis más grave desde las guerras civiles del siglo xIX. Los importantes logros del proceso bolivariano están en peligro. La economía se derrumba, la pobreza, la desnutrición y las tasas de mortalidad están aumentando. La polarización política y la violencia podrían conducir a una guerra civil. Todo esto está agravado por el creciente aislamiento internacional debido, entre otras cosas, al giro a la derecha de los gobiernos de Brasil y Argentina, y acciones imperialistas como el bloqueo financiero y las amenazas de intervención militar realizadas por Donald Trump.

La crisis venezolana no es nueva. El país ha estado experimentando una profunda crisis económica y política estructural durante las últimas cuatro décadas. Es la crisis terminal del modelo petrolero rentista, estatista y clientelar que ha caracterizado a la sociedad venezolana desde hace muchas décadas. Sin embargo, este modelo rentista extractivo tuvo un nuevo soplo de vida con el liderazgo carismático de Chávez, la legitimidad proporcionada por la Constitución de 1999 y los altos precios del petróleo de los primeros años de este siglo. Una vez más, parecía que los precios del petróleo solo podían ir hacia arriba. Los ingresos procedentes del petróleo fueron vistos en el corto y mediano plazo, como la fuente de los recursos necesarios para la transformación de la sociedad venezolana. Durante los ańos del proceso bolivariano no se tomaron medidas significativas de transformación de la estructura productiva del país. Por el contrario, se profundizó el rentismo petrolero hasta que el petróleo alcanzó el 96\% del valor total de las exportaciones. Hoy el país es más dependiente que nunca en su historia de las importaciones, incluso de alimentos básicos y suministros médicos.

Las políticas sociales que mejoraron sustancialmente las condiciones de vida de los sectores populares y las importantes iniciativas hacia otros países de América Latina, la cooperación y la solidaridad llevada a cabo por el gobierno venezolano, fueron posibles gracias a un extraordinario auge de la demanda y precio de los commodities generado principalmente por la demanda china. En la medida en que la renta petrolera se dirigió principalmente hacia los sectores excluidos de la población, se produjeron significativas mejoras en sus condiciones de vida. La pobreza y la desigualdad se redujeron notoriamente, el acceso a alimentos, servicios de salud, educación y seguridad social mejoró en términos cualitativos. Políticamente se iniciaron profundos cambios en la cultura política popular, se generalizó la organización social de base y se produjeron extraordinarios niveles de participación social y política. Venezuela desempeñó un papel central en el desplazamiento a la izquierda que ocurrió en la mayor parte de América del Sur. Durante años, el gobierno contó con elevados niveles de legitimidad y apoyo electoral.

Sin embargo, en 2013 y 2014, los dos principales pilares que sostuvieron el proceso bolivariano, el extraordinario liderazgo carismático de Chávez y los elevados precios del petróleo, dejaron de estar presentes. Chávez falleció el 5 de marzo de 2013. Un año más tarde, el precio de las exportaciones de petróleo venezolano se había derrumbado de más de cien dólares el barril a menos de 25 dólares. Así, la profunda crisis terminal del Estado, la economía y la sociedad rentista petrolera que había sido, en cierto sentido, aplazada durante unos años, resurgió con mayor, incluso dramática, intensidad.

\section{La situación económica y social}

Para analizar el estado actual de la economía en Venezuela no existe información oficial actualizada disponible. El gobierno ha decidido no revelar la información estadística que permitiría confirmar la profundidad de la actual crisis económica. ${ }^{1}$ Los cálculos que se han difundido por parte de analistas económicos, centros académicos, asociaciones empresariales e instituciones internacionales presentan grandes variaciones. No todos son confiables.

En el año 2016 la economía venezolana registró su peor caída desde el paro petrolero/lock-out empresarial de los años 2002-2003, con una contracción que se

1 Se trata principalmente de las estadísticas que deberían ser dadas a conocer por el Instituto Nacional de Estadística, el Banco Central de Venezuela y el Ministerio de Hacienda. Algunas estadísticas básicas tienen dos ańos o más sin ser divulgadas. 
ha estimado entre $10 \%^{2}$ y $18.6 \%$. Se acumularon así tres años consecutivos de disminución del PIB. Según algunas estimaciones, el colapso de la economía venezolana ha sido tal que, en 2017, el PIB per cápita representa un $40 \%$ de los niveles del año $2013 .{ }^{3}$ Los precios del petróleo se recuperaron de un promedio de 35 dólares por barril en 2016 a 42 dólares por barril en abril de $2017,{ }^{4}$ aún lejos de los precios que oscilaron entre 101 y 88 dólares por barril entre 2011 y 2013. No solo los precios han colapsado, según la OPEP, la producción de petróleo ha caído a un millón 972 mil barriles diarios. ${ }^{5}$ Esto es casi un millón de barriles menos de los que se producían en el año 2001. Este descenso se ha atribuido a la ineficiencia, corrupción, falta de inversión, y al hecho de que es mucho más complejo y costoso explotar el crudo pesado y extra pesado que hoy constituye la mayor parte de las reservas venezolanas. Petróleo liviano o gasolina tiene que ser importado para ser mezclado con este petróleo pesado para su transporte y refinación, lo que reduce significativamente los beneficios. De acuerdo a dirigentes sindicales de la industria petrolera, la refinería principal del país, uno de los complejos de refinación más grandes del mundo, está trabajando a menos del 50\% de su capacidad instalada debido a la falta de mantenimiento adecuado. ${ }^{6}$

Según los Estados Financieros Consolidados de la empresa petrolera estatal (PDVSA) correspondientes al año 2016, el beneficio neto de ésta se desplomó de más de nueve mil millones de dólares en 2014 a 828 millones de dólares en 2016.7 Esta empresa, la fuente de la mayor parte de los ingresos del país, al igual que el resto del Venezuela, se encuentra en una profunda crisis.

Diferentes fuentes, tanto nacionales como internacionales, han calculado que la inflación en 2016

2 World Bank. Venezuela Overview, Washington, 6 de octubre, 2016. [http://www.bancomundial.org/en/country/venezuela/overview]

3 Ricardo Hausmann, «El colapso de Venezuela no tiene precedentes», Prodavinci, Caracas, 31 de julio de 2017.

[http://prodavinci.com/2017/07/31/actualidad/

el-colapso-de-venezuela-no-tiene-precedentes-por-ricardo-hausmann/]

4 Ministerio del Poder Popular para el petróleo. Precios del petróleo, Caracas, 30 de abril de 2017. [http://www.mpetromin.gob.ve/ portalmenpet/secciones.php?option=view\&id=45]

5 OPEC, Monthly Oil Market Report, 12 de abril, 2017, p. 55.

[http://www.mpetromin.gob.ve/portalmenpet/secciones. php?option=view\&idS=45]

6 Centro de Refinación de Paraguaná opera un 42 por ciento de su capacidad, La Patilla, Caracas, 17 de agosto de 2017.

7 Petróleos de Venezuela, S.A. y sus filiales (PDVSA), Estados Financieros Consolidados, Caracas, 31 de diciembre de 2016. se situó entre $500 \%$ y $800 \%{ }^{8}$, se esperan niveles más altos para el año 2017. Por tercer año consecutivo se ha producido un grave déficit fiscal. Según algunas estimaciones, el gasto público en 2016 tuvo una reducción de alrededor del $30 \%$ en comparación con el nivel del año anterior. ${ }^{9}$

Las reservas internacionales disminuyeron de 35 mil millones de dólares en 2009 a 10.300 millones de dólares en abril de 2017. ${ }^{10}$ La formación de capital fijo ha venido disminuyendo desde 2013. La misma tendencia está presente en el consumo privado.

El total de la deuda consolidada del país (es decir, deudas nacionales y externas pagaderas en dólares, préstamos y bonos emitidos por la República y PDVSA), ascienden a 181 mil millones de dólares. Esto representa más del $80 \%$ del PIB, y es casi 18 veces más que el total de las reservas internacionales del país. ${ }^{11}$ Todo esto, a pesar del hecho de que durante los 18 años del proceso bolivariano Venezuela experimentó un auge sin precedentes de los precios del petróleo. Durante este período, el país recibió más dólares que los que habían ingresado al país durante las anteriores ocho décadas de exportaciones petroleras. Este enorme endeudamiento externo, como en experiencias anteriores, se produjo precisamente en los años de bonanza, cuando los precios del petróleo eran muy elevados. Parte de esta deuda es una deuda ilícita que sirvió de alimento a la corrupción. Grupos e intelectuales de izquierda han exigido al gobierno la realización de una auditoría pública de esta deuda, como se realizó en Ecuador, y que en el ínterin se lleve a cabo una renegociación que permita una reducción de los pagos.

Incluso ante la realidad de una grave crisis humanitaria, el gobierno venezolano ha dado prioridad al pago de la deuda a tiempo sobre las necesidades urgentes de la población venezolana. De acuerdo al Ministerio del Poder Popular de Petróleo, «En los últimos 36 meses, Venezuela ha cancelado, por concepto de Capital Reembolsado y de Intereses Pagados, la cantidad de 73 mil 359 millones de

8 «La inflación en 2016 cerró en casi 800\%, "Informe 21.com, Caracas, 21 de enero de 2017. [https://informe21.com/economia/ inflacion-de-2016-habria-cerrado-en-casi-800]

9 «En 30,8\% cayó el gasto público del gobierno el ańo pasado», $E l$ Universal, Caracas, 24 de enero 2017, [http://www.eluniversal.com/ noticias/economia/308-cayo-gasto-del-gobierno-ano -pasado_636539]

10 Oly Angélica Millán Campos, «La situación actual del problema de la deuda", la Asamblea Regional anual del Comité para la anulación de las deudas ilegítimas», CADTM AYNA, Bogotá, abril de 2017.

11 Ídem. 
dólares». ${ }^{12} \mathrm{Al}$ mismo tiempo la organización de caridad de la Iglesia Católica, Cáritas Internacional, el $54 \%$ de los niños venezolanos tienen algún grado de desnutrición. ${ }^{13}$ Esto es, principalmente, una consecuencia de la drástica disminución de los recursos disponibles para la importación en un país que tiene un nivel tan elevado de dependencia externa para sus alimentos y medicinas.

Una de las más importantes distorsiones históricas de la economía petrolera venezolana ha sido una moneda sobrevaluada que ha hecho que sea más barato importar la mayoría de las cosas que producirlas internamente. Esto, al mismo tiempo, ha operado como una barrera que dificulta exportar prácticamente nada aparte del petróleo. Esta es la mal llamada enfermedad holandesa. Venezuela la había padecido durante décadas antes del descubrimiento de de los depósitos de gas por parte de Holanda. El país se hizo altamente dependiente de las importaciones, incluso de alimentos básicos. Se trata, propiamente, de una economía de puerto.

El gobierno bolivariano ni siquiera comenzó a corregir las distorsiones cambiarias. A fin de limitar la fuga de capitales, se crearon a lo largo de estos años varios sistemas de control cambiario que generaron distorsiones aun más severas con la creación de varios tipos de cambio paralelos, tanto legales como ilegales. A veces, hasta cuatro tasas cambiarias operaron en forma simultánea. Mientras la paridad altamente subvencionada con que se importa la mayor parte de los alimentos básicos y medicinas ha permanecido fija durante años en 10 bolívares por dólar, la paridad en el mercado paralelo ilegal, que tiene un impacto significativo en la estructura de precios del país, que osciló entre 10.000 y 18.000 bolívares por dólar en agosto de este año, sobrepasó los 80.000 bolívares a finales de noviembre de 2017.

El deterioro general de la actividad productiva y de las finanzas públicas ha tenido graves repercusiones en las condiciones de vida de la población, especialmente en las áreas de salud, alimentación y la inseguridad personal. Esto constituye una reversión de los más importantes logros sociales del proceso bolivariano. Los

12 Ministerio del poder Popular de Petróleo, Comunicado del encuentro para el refinanciamiento de la deuda externa, Caracas 13 de noviembre de 2017, [http://www.pdvsa.com/index.php?option=com_cont ent \&view=article \&id=8516: comunicado-del-encuentro-para-elrefinanciamiento-de-la-deuda-externa $\&$ catid $=10$ : noticias $\&$ Itemid $=$ 589\&lang=ese-60-millones-de-dolares-ha-cancelado-venezuela-encompromisos-internacionales-video/]

13 «Cáritas: el $54 \%$ de los niños en Venezuela tienen deficiencias nutricionales», Web de El Nacional, Caracas, 28 de agosto de 2017. niveles de pobreza en términos de ingresos monetarios, que se habían reducido significativamente entre 1999 y 2012, hoy están peor que los niveles que existían antes del inicio del gobierno de Chávez.

La drástica reducción de las divisas disponibles para financiar las importaciones ha creado una escasez generalizada de medicamentos y complica considerablemente el tratamiento de enfermedades crónicas como la hipertensión y la diabetes. Ha habido una pérdida en el peso promedio de la población. Son frecuentes las muertes en hospitales, consecuencia directa de la falta de medicamentos y equipamiento médico, así como la desnutrición infantil. Las tasas de mortalidad de las parturientas y los recién nacidos se ha incrementado significativamente en los últimos tres ańos. ${ }^{14}$ Hoy en día existe una severa epidemia de malaria que se ha expandido en forma acelerada en los últimos años. Entre los años 2015 y 2016, el número de casos registrados en el país se incrementó en un $76 \%$, pasando de 136.402 a 240.613 casos. ${ }^{15}$ Las carencias de medicamentos y los desplazamientos poblacionales hacia las zonas de explotación minera del Estado Bolívar, principal foco de la epidemia, agrava la situación.

Según el Observatorio de la Violencia en Venezuela, en 2016, el país tuvo una tasa de homicidios de 91 homicidios por cada 100.000 habitantes, en segundo lugar después de El Salvador en todo el mundo ${ }^{16}$ Aunque no hay cifras oficiales, se estima que unas dos millones de personas han abandonado el país en los últimos tres años, especialmente jóvenes, tanto profesionales como trabajadores no calificados, en busca de un futuro mejor en otros lugares.

La decisión económica más importante realizada por el gobierno de Maduro en los últimos años ha sido el decreto de creación del Arco Minero del Orinoco. Es la apertura de 112 mil kilómetros cuadrados, el $12 \%$ del territorio nacional, a grandes empresas mineras transnacionales. Se trata de un área económica especial en la cual quedan suspendidas muchas leyes fundamentales de la República. Frente a la crisis del modelo petrolero rentista, en lugar de

14 Ministerio del Poder Popular para la Salud, Boletín Epidemiológico, Caracas 25 al 31 de diciembre 2016.

[https://www.scribd.com/document/347856274/BoletinEpidemiologico-el-Ministerio-del-Poder-Popular-para-la-Salud]

15 Ídem.

16 "2016: OVV estima 28.479 muertes violentas en Venezuela», Observatorio Venezolano de Violencia, Caracas, diciembre de 2016. [http://observatoriodeviolencia.org.ve/2016-ovv-estima-28-479muertes-violentas-en-venezuela/] 
promover un debate nacional sobre las alternativas al modelo extractivista depredador que ha caracterizado la economía venezolana durante un siglo, el gobierno ha optado por empujar al país en el camino de un nuevo patrón rentista-extractivista, ahora basado en la minería a gran escala. Este megaproyecto, en caso de llevarse a cabo en la dimensión que ha sido anunciada por el gobierno, profundizaría las dinámicas etnocidas hacia los pueblos indígenas que en la actualidad se producen como consecuencia de la minería ilegal. Tendría devastadoras consecuencias socio-ambientales tanto inmediatas como a largo plazo. Afectaría parte de la foresta amazónica, destruyendo vastas áreas de extraordinaria diversidad biológica, amenazaría las principales fuentes de agua, así como las represas hidroeléctricas que suministran el $70 \%$ de la electricidad que se consume en el país.

\section{La pérdida de hegemonía y las tendencias autoritarias}

Cuando Nicolás Maduro llegó a la presidencia, en abril de 2013, lo hizo con un nivel de legitimidad y de apoyo electoral mucho más bajo que el que tuvo Chávez hasta su muerte. Ganó las elecciones con una diferencia de solo $1,5 \%$ sobre Henrique Capriles, el candidato de la oposición articulada en la Mesa de la Unidad Democrática (MUD).

Una ruptura fundamental en el proceso bolivariano se produjo cuando, con la victoria aplastante en las elecciones parlamentarias del 6 de diciembre de 2015, la oposición alcanzó una mayoría cualificada de dos tercios en la Asamblea Nacional (AN). Esto implicaba un cambio radical en la correlación de fuerzas en el seno del Estado. Con esta mayoría, la oposición en la AN, de acuerdo a la Constitución, podía nombrar a los miembros del Tribunal Supremo de Justicia (TSJ) y del Consejo Nacional Electoral (CNE). Podría aprobar leyes orgánicas sin negociar con los representantes del gobierno. En lugar de reconocer esta severa derrota e iniciar una profunda reflexión autocrítica sobre sus causas, el Gobierno no vio la necesidad de cambios en sus políticas y atribuyó la crisis y la victoria de la oposición exclusivamente a lo que ha denominado la "guerra económica» por parte de la derecha y del imperio. Estos son asuntos reales pero no son, en sí mismos, suficientes para explicar la profunda crisis económica del país o los niveles de descontento en la población. Temas claves como la corrupción generalizada, la ineficiencia de la administración pública o las distorsiones que genera una paridad cambiaria insostenible, fueron una vez más dejados a un lado. En lugar de dar prioridad a la preservación de la experiencia colectiva y el espíritu combativo del mundo popular bolivariano, que representa el más extraordinario logro de este proceso político, optó por permanecer en el control del Estado por cualquier medio necesario. A partir de ese momento, el Gobierno parece reconocer que no podía permanecer en el poder si esto dependía del apoyo electoral de la población, y de acatar la Constitución bolivariana del año 1999. Se han realizado repetidos llamamientos al poder popular y a dicha Constitución, pero, en la práctica, estos se convierten en obstáculos a superar. Por ello, se fueron tomando una serie de decisiones que, en conjunto, apuntan en una forma cada vez más sistemática y coherente en una dirección autoritaria que tiene como prioridad la preservación del control del poder del Estado.

Las graves violaciones que se han producido a la Constitución de 1999 y a normas legales básicas en los últimos tres años son demasiadas para ser analizadas en detalle. Sin embargo, algunas de estas deben destacarse con el fin de comprender cómo se llegó a la situación actual. A finales de diciembre de 2015, cuando a la mayoría del gobierno en la AN le quedaban pocos días antes de que la nueva mayoría opositora tomara control, dicha mayoría oficialista, dejando de lado algunos procedimientos exigidos por la ley, designó nuevos magistrados del TSJ. No solo eran estos nuevos magistrados, sin excepción, aliados incondicionales del gobierno, sino que varios de ellos ni siquiera cumplían los requisitos formales requeridos para ocupar dichos cargos.

El papel que este tribunal iba a jugar en estas nuevas condiciones del país se hizo evidente poco después. A principios de 2016, basado en una endeble acusación de fraude electoral formulada por algunos miembros del partido de gobierno, este Tribunal decidió anular los resultados de las elecciones en el estado de Amazonas. Decidió que la elección de los cuatro representantes del Estado, en su mayoría indígenas, y que ya habían sido proclamados por el CNE, ya no era válida. Así, los partidos de la oposición dejaron de tener una mayoría cualificada en la AN.

En vista del hecho de que transcurrieron meses sin que se llevase a cabo una investigación para determinar 
la veracidad de estas acusaciones ni se programaran nuevas elecciones para ese estado, el estado Amazonas quedó sin representación parlamentaria. Finalmente, la AN decidió incorporar a los parlamentarios cuestionados y el TSJ respondió declarando a la Asamblea en desacato. A partir de este momento, sus atribuciones fueron asumidas por el Poder Ejecutivo y dicho tribunal. Este fue un momento decisivo en la ruptura del orden constitucional, produciendo la concentración de poderes que ha permitido al Gobierno tomar cada uno de los pasos subsiguientes que han definido su deriva autoritaria.

Una de las principales fortalezas institucionales del proceso bolivariano y un poderoso escudo protector contra los intentos de la derecha nacional e internacional y del gobierno de los Estados Unidos para derrocar al gobierno, fue la legitimidad proporcionada por un sistema electoral totalmente automatizado, transparente, altamente fiable, que contaba con muchos niveles de controles y auditorías. Durante las múltiples elecciones celebradas hasta 2015, este sistema electoral garantizó que los resultados anunciados por el órgano electoral fueran, sin duda alguna, una expresión exacta de la voluntad de los electores. Sin embargo, después de la derrota sufrida en las elecciones legislativas de diciembre de 2015, el gobierno optó por sacrificar este escudo protector para mantenerse en el poder. Esto ha tenido enormes consecuencias políticas.

En octubre de 2016, el CNE canceló el referéndum revocatorio del Presidente. Todos los requisitos establecidos por la ley estaban en proceso de cumplirse. El referéndum revocatorio hasta ese momento había sido celebrado como uno de los más importantes logros de la democracia participativa de la Constitución de 1999. Las elecciones para gobernadores que, según la Constitución tenían que ser celebradas en diciembre de 2016, fueron aplazadas indefinidamente.

En marzo de 2017, el TSJ ratificó que la AN estaba en desacato y, entre otras cosas, autorizó al Presidente a tomar medidas adicionales en la apertura del país a las empresas transnacionales de petróleo y minería en condiciones expresamente prohibidas por la Constitución, por la Ley Orgánica de Hidrocarburos, la legislación ambiental, la referida a los pueblos indígenas y las leyes laborales.

Luisa Ortega Díaz, Fiscal General de la República, declaró que estas decisiones atentaban contra el modelo de Estado consagrado en la Constitución y que esto representaba una «ruptura del hilo constitucional».
Ante el rechazo generalizado de estas decisiones, el TSJ modificó algunos aspectos menores sin alterar sus contenidos fundamentales. ${ }^{17}$

Desde febrero de 2016, el presidente Maduro ha gobernado mediante decretos de excepción y emergencia económica en condiciones que violan claramente la Constitución. Con este estado de excepción, muchas garantías constitucionales pueden ser suspendidas, y decisiones fundamentales para el futuro del país, como las relativas a la minería en el Arco Minero del Orinoco, pueden ser tomadas por decreto presidencial. El presupuesto nacional correspondiente al año 2017 no fue presentado a la AN como lo exige la Constitución, negando así a esos representantes elegidos el derecho a tener algo que decir sobre la gestión de los recursos públicos y sobre la orientación de las políticas públicas. Esto añade una nueva capa de opacidad en la gestión de los bienes colectivos.

\section{La Asamblea Nacional Constituyente}

El primero de mayo de 2017, el Presidente Maduro anunció que había decidido convocar a una nueva Asamblea Constituyente. En este mismo discurso declaró el fin de la Constitución de 1999, situándola en la categoría de antecedente histórico, una Constitución «pionera». Inmediatamente se generó una gran polémica, dentro y fuera de Venezuela. En ese clima político extremamente polarizado, este debate estuvo lleno de distorsiones y medias verdades. Según el gobierno, el propósito de la Asamblea Constituyente fue el de garantizar la paz en el país después de meses de violentos enfrentamientos callejeros. Sectores de la oposición venezolana denunciaron que el verdadero objetivo era evitar las próximas elecciones (estatales, municipales y presidenciales) y caracterizaron esto como un golpe de Estado.

Es necesario reconocer que, en la Constitución, las condiciones para la convocatoria de una Asamblea Constituyente no son totalmente explícitas. Según el Artículo 348: "La iniciativa de convocar a una Asamblea Nacional Constituyente puede ser tomada por el Presidente de la República en Consejo de Ministros...» Sin embargo, hay una diferencia

17 Plataforma ciudadana en defensa de la Constitución, «El hilo constitucional que sigue roto. Por el restablecimiento de la Constitución», Aporrea, Caracas, 14 de abril de 2017. [www.aporrea. org/actualidad/a244201.html] 
entre "convocatoria», que la Constitución atribuye expresamente al "pueblo de Venezuela... depositario del poder constituyente originario» y «tomar la iniciativa de convocar». En consecuencia, aunque el Presidente puede tomar la iniciativa, la convocatoria como tal, debería haberla hecho la ciudadanía a través de un referéndum consultivo, como fue el caso de la Asamblea Constituyente de 1999.

Es evidente que las principales dificultades que enfrenta el país (escasez, malnutrición, crisis del sistema de salud, inflación, inseguridad, recesión, déficit fiscal y una deuda externa que no puede ser pagada, etc.) no son problemas normativos que pueden resolverse con un nuevo orden jurídico. Los problemas que se plantean en relación con la Constitución de 1999 están en sus violaciones sistemáticas, no en su contenido.

Otra ruptura radical con la Constitución de 1999 y las leyes electorales se produjo con el diseño del proceso electoral para la nueva Asamblea Nacional Constituyente (ANC). En clara violación de los principios constitucionales de la representación proporcional y la igualdad de los electores, las normas para la participación electoral fueron cuidadosamente diseñadas de tal forma que el gobierno se garantizaba el control completo de esta nueva asamblea, a pesar de que la mayoría de la población no respaldase al gobierno y rechazase la convocatoria de una nueva asamblea constituyente. Esto se hizo mediante la creación de un original régimen de doble representación: territorial y sectorial. Contrariamente a la forma en la que siempre habían sido realizadas las elecciones en el país, antes y durante el gobierno bolivariano, a las zonas rurales o pequeños municipios urbanos, donde el gobierno ha contado con mayor respaldo electoral, les fue otorgada una extraordinaria sobre representación en la asamblea. En algunos casos, a un municipio rural con menos de 3000 habitantes se le asignó el mismo número de representantes que a un municipio urbano con más de 700.000 habitantes: un total de uno. Se definió adicionalmente un mecanismo de representación sectorial en el cual los estudiantes votaron por estudiantes, los trabajadores por trabajadores, etc. Unos cinco millones de votantes fueron excluidos de la participación en la elección de los representantes sectoriales ya que no pertenecían a ninguno de los sectores sociales así definidos. Esto creó dos tipos de ciudadanos, unos de primera clase, que podían votar dos veces (un voto territorial y uno sectorial), y otros de segunda clase que solo podían votar una vez (voto territorial). Como consecuencia del carácter arbitrario e inconstitucional de este proceso, solo organizaciones que respaldan al gobierno presentaron candidatos y participaron en las elecciones, convirtiéndolas prácticamente en unas elecciones internas del PSUV.

Las elecciones para esta ANC constituyeron un fraude. Antes de las elecciones, portavoces del gobierno y del PSUV afirmaron en forma pública y reiterada que se llevaría un control estricto de los votantes y que quienes no participasen en estas elecciones perderían su empleo público, o la posibilidad de tener acceso a programas sociales tales como el de alimentación subsidiada (CLAP) y vivienda. Estos anuncios públicos fueron complementados por amenazas personales en los lugares de trabajo y centros de distribución de alimentos. La democracia participativa de los primeros años del proceso bolivariano se había desplazado hacia una relación de control crecientemente autoritaria desde el Estado, basado en chantajes y amenazas.

Las elecciones se realizaron sin testigos independientes o de la oposición y a los medios de comunicación se los mantuvo a unos 500 metros de los centros de votación. Varios de los más importantes mecanismos de control y auditoría que habían hecho que el sistema electoral venezolano fuese altamente confiable fueron eliminados. Incluso con los niveles de participación muy inflados anunciados por el CNE, casi el $60 \%$ de la población no votó.

Un nuevo giro del tornillo, que alejó al gobierno de Maduro aun más de la democracia y de la Constitución de 1999, se produjo cuando la nueva ANC fue instalada. Como en los viejos tiempos del socialismo realmente existente, se trata de una asamblea unipartidista, cada uno de sus 545 integrantes es oficialista. El que la Asamblea Nacional Constituyente encargada de redactar una nueva constitución en un país tan profundamente dividido como Venezuela sea absolutamente monocromática no es un buen augurio para el futuro de la democracia o la paz en el país. El proceso constituyente ha revivido parte del apoyo popular menguante al gobierno, ya que fue presentado como una radicalización del proceso, como un enfrentamiento con el imperialismo, y como una solución a los problemas que enfrenta la población. Esto, sin embargo, es probable que tenga poca duración ya que el gobierno carece de la capacidad o los recursos para hacer frente a estos problemas.

La ANC se ha declarado como un poder absoluto, supra constitucional, que puede no solo redactar 
una nueva constitución, sino tomar decisiones sobre cualquier asunto legislativo, ejecutivo o judicial que considere conveniente. Su período de vigencia no ha sido fijado. Declaró que las cinco ramas de Estado existentes deberán subordinarse a sus decisiones. En sus primeras semanas de actividad, sus decisiones fueron tomadas por unanimidad o por aclamación, sin debate alguno. Leyes extraordinariamente autoritarias y represivas han sido anunciadas. En el mes de noviembre se aprobó una ley que establece penas de 10 a 20 ańos de prisión por «incitación al odio» en los periódicos, la radio, la televisión y las redes sociales, la denominada Ley Constitucional Contra el Odio, por la Convivencia Pacifica y la Tolerancia. Igualmente amenazantes han sido los anuncios de que dirigentes de la oposición serían acusados de traición a la patria por su apelación a instituciones internacionales como la OEA y la ONU. Estas amenazas están dirigidas no solo hacia la oposición de derecha, sino contra toda oposición al gobierno. Los espacios para el ejercicio de la democracia continúan reduciéndose...

\section{La escalada de la violencia}

En los años del gobierno bolivariano la oposición agrupada en la MUD ha sido muy heterogénea. Incluye desde grupos de extrema derecha que han tenido el apoyo político y financiero externo (básicamente del gobierno de los Estados Unidos y el uribismo en Colombia), hasta sectores más moderados que han buscado alternativas electorales, constitucionales. En la actualidad estas diferencias subsisten a pesar de la apariencia de unidad que se dio entre abril y julio en las masivas movilizaciones de calle en todo el país y el acuerdo casi unánime para participar en las elecciones para gobernadores del mes de octubre de 2017. Esto a pesar del hecho de que el CNE ha abandonado toda pretensión de ser un árbitro neutral y confiable.

Se produjeron niveles extremos de violencia durante los meses de abril y julio. Al menos 150 personas murieron en enfrentamientos callejeros. Esto fue el resultado tanto de la represión policial/militar, como de la acción de grupos paramilitares armados que operaron en ambos lados de estas confrontaciones. En algunos casos particularmente grotescos, algunos chavistas fueron quemados por turbas de la extrema derecha. Como era de esperarse en una situación tan polarizada, la cobertura de estos acontecimientos por parte de los medios internacionales fue muy distorsionada. El conflicto venezolano ha sido interpretado a través de los lentes de la Guerra Fría. Las narrativas sesgadas según las cuales las más de un centenar de muertes fueron el producto exclusivo de la represión gubernamental, o la narrativa contraria de acuerdo a la cual estas muertes fueron principalmente el resultado de grupos armados fascistas, simplemente no corresponden a lo ocurrido. La situación es más compleja. Ha habido acciones violentas en ambos lados en estas confrontaciones.

La sociedad venezolana se enfrenta al grave peligro de que la violencia armada y el terrorismo puedan instalarse como la forma normal de procesar las diferencias. El peligro no es solo que la violencia se desborde a niveles no deseados por los líderes del gobierno y la oposición. En ambos polos de la confrontación actual hay sectores que ven la violencia como única forma de derrotar al enemigo e imponer su agenda.

Algunos de los más altos funcionarios corruptos del gobierno se dan cuenta de que si fueran obligados a abandonar sus cargos, no solo perderían sus privilegios, sino que también les resultaría difícil encontrar un lugar en el mundo donde disfrutar de sus fortunas mal habidas y que incluso podrían terminar en la cárcel.

Lo que algunos sectores de extrema derecha buscan no es simplemente una victoria electoral para sustituir a Maduro, si esto dejase intacta la Constitución de 1999, y se mantuviese vida por lo menos parte de los imaginarios transformadores de los sectores populares chavistas de base. Lo que quieren es un completo aplastamiento de la experiencia chavista, de todos los sueños emancipatorios de la primera década del proceso bolivariano, a fin de imponer una derrota política de larga duración que sirva como una lección y liquide, de una vez por todas, las aspiraciones y el espíritu rebelde subalterno de estos años. Se considera que esto es un requisito básico para que la sociedad regrese a la «normalidad», donde todo el mundo asuma su lugar. Las consecuencias de esto van mucho más allá de Venezuela. Para ello han contado siempre con el apoyo del gobierno de los Estados Unidos.

\section{La corrupción}

Una adecuada caracterización de los mecanismos y la dimensión de la corrupción durante el proceso 
bolivariano es una tarea pendiente. En agosto de 2013, Edmée Betancourt fue removida de su cargo como presidenta del Banco Central de Venezuela (BCV) por denunciar que en ese año más de 20 mil millones de dólares altamente subsidiados fueron entregados por la Comisión de Administración de Divisas (Cadivi) a «empresas de maletín» para importaciones y actividades productivas que nunca tuvieron lugar. ${ }^{18}$ Casi un año más tarde, después de su separación del Ministerio de Planificación, Jorge Giordani, un conocido bastión de los gobiernos del presidente Chávez, divulgó su carta de Testimonio y responsabilidad ante la historia en la cual confirmó y profundizó las denuncias que había formulado Edmée Betancourt. ${ }^{19}$

La grave falta de transparencia en las finanzas públicas hace extremadamente difícil determinar la magnitud de la corrupción. Según diversas estimaciones, el monto global de la corrupción durante la última década supera los 300 mil millones de dólares. Esto cubre una amplia gama de actividades, entre ellas el acceso ilícito a divisas subvencionadas, la especulación con bonos venezolanos (comprados en bolívares, luego vendidos en dólares), sobre-facturación de las importaciones, sobornos y comisiones en contratos de PDVSA y en grandes obras de infraestructura, como fue el caso en las relaciones con la constructora brasileña Odebrecht.

\section{Movimientos y organizaciones populares ante la crisis}

Las reacciones subalternas ante el profundo deterioro de las condiciones de vida que se han producido como consecuencia del aumento de la inseguridad, (debido tanto a la delincuencia como a la represión policial), una inflación desbordada, la escasez de alimentos básicos y medicamentos y el deterioro de los servicios públicos, no ha sido, en términos generales lo que podría haberse esperado. Muchas de las organizaciones de base populares que han involucrado a millones de personas en estos años se habían vuelto tan dependientes de los recursos públicos transferidos por instituciones del Estado que se debilitan cuando estos recursos ya no están disponibles. La crisis ha llevado a

18 Presidenta del BCV: Parte de los \$59.000 millones entregados en 2012 fueron un "empresas de maletín», Aporrea/AVN, Caracas, 24 de mayo de 2013. [www.aporrea.org/actualidad/n229466.html]

19 [https://www.aporrea.org/ideologia/a190011.html] un creciente desencanto con el gobierno y la pérdida de expectativas en relación con el futuro del país. Después de años de procesos de movilización y organización popular, guiados por los valores de la cooperación y la solidaridad, la reacción a la crisis actual se ha caracterizado en buena medida por la competencia y el individualismo. El bachaqueo se ha convertido en un componente importante de la economía venezolana. ${ }^{20}$ Se han producido saqueos masivos en varias ciudades de todo el país con diversas combinaciones de activismo militante de grupos de extrema derecha, organizaciones delictivas y protesta popular espontánea debido a la falta de acceso a alimentos y gas para cocinar. El tejido social y moral del país están gravemente desgarrados. Esto tardará muchos ańos en cicatrizar.

\section{La «comunidad internacional» y Venezuela}

Los intentos imperiales de debilitar o derrocar el gobierno bolivariano han tomado muchas formas, tales como el apoyo político y financiero a los sectores más radicales de la oposición, el respaldo al golpe de Estado de abril de 2002 y los intentos de aislar al país internacionalmente. Más recientemente, Barack Obama, justo antes de terminar su mandato renovó una orden ejecutiva que declaraba que Venezuela era «una inusual y extraordinaria amenaza a la seguridad nacional y la política exterior de los Estados Unidos». ${ }^{21}$

En un informe presentado al Comité de las Fuerzas Armadas del Senado de los Estados Unidos en abril de este año, Kurt W. Tidd, Jefe del Comando Sur, afirmó que:

Venezuela se enfrenta a una significativa inestabilidad en este próximo año debido a la generalizada escasez de alimentos y medicinas, la incertidumbre política y el deterioro de las condiciones económicas. La creciente crisis humanitaria en Venezuela podría eventualmente obligar a una respuesta regional. ${ }^{22}$

20 Esto es básicamente la compra o robo de productos básicos altamente subsidiados por el Estado para su reventa a precios especulativos y el contrabando de extracción, sobre todo a Colombia.

21 The White House, Office of the Press Secretary. Notice. Continuation of the National Emergency with Respect to Venezuela, Washington, 13 de enero de 2017.

[https://obamawhitehouse.archives.gov/the-press-office/2017/01/13/ notice-continuation-national-emergency-respect-venezuela]

22 Posture Statement of Admiral Kurt W. Tidd Commander, United States Southern Command before the 114th Congress Senate Armed Services Committee March 10, 2016. [https://www.armed-services. senate.gov/imo/media/doc/Tidd_04-06-17.pdf] 
En agosto de 2017, Donald Trump amenazó a Venezuela con una intervención militar de los Estados Unidos en los siguientes términos:

Tenemos muchas opciones para Venezuela y por cierto, no voy a descartar una opción militar.

Tenemos muchas opciones para Venezuela, este es nuestro vecino... Estamos en todo el mundo y tenemos tropas en todo el mundo, en lugares que están muy lejos, Venezuela no está muy lejos y la gente está sufriendo y muriendo. Tenemos muchas opciones para Venezuela, incluida una posible opción militar si es necesario. ${ }^{23}$

Se dio un paso más el 24 de agosto de 2017, cuando Donald Trump ordenó un bloqueo financiero de Venezuela. Esta amplia gama de prohibiciones incluye la negociación de nuevas deudas públicas y bonos emitidos por el gobierno venezolano, el pago de dividendo u otra distribución de utilidades al Gobierno de Venezuela o a cualquier entidad que sea propiedad o esté controlada, directa o indirectamente, por el Gobierno de Venezuela, así como la compra, directa o indirectamente, por Estados Unidos o una persona dentro de los Estados Unidos, de títulos o valores emitidos por el gobierno venezolano. ${ }^{24}$

En contraste con las anteriores sanciones aplicadas directamente a altos funcionarios de gobierno, este bloqueo financiero puede tener un severo impacto sobre el conjunto de la población. En las condiciones actuales de grave crisis que está atravesando el país, incluyendo un considerable déficit del sector externo, el gobierno ha enfrentado enormes dificultades en el acceso a los mercados financieros internacionales. Como consecuencia del mayor «riesgo país» en las Américas, solo puede obtener nuevos préstamos a tasas de interés muy elevadas. Como se señaló arriba, hoy carece de los recursos para importar los alimentos y medicamentos básicos requeridos por la población. Este bloqueo financiero podría conducir al país a un default y con seguridad haría que el acceso al financiamiento externo sea más restringido y costoso. La coalición de derechas organizada en la MUD emitió un comunicado dando

23 Ben Jacobs, «Trump threatens 'military option' in Venezuela as crisis escalates», The Guardian, Londres, 12 de agosto 2017. 12 de agosto de 2017.

24 Donald Trump, «Executive order. Imposing additional sanctions with respect to the situation in Venezuela», Washington, 24 de agosto 2017. [https://www.whitehouse.gov/the-press-office/2017/08/25/ presidential-executive-order-imposing-sanctions-respect-situation] la bienvenida a estas sanciones. ${ }^{25} \mathrm{La}$ guerra económica que venía denunciando el gobierno venezolano en los últimos años ha llegado con fuerza.

La respuesta del gobierno venezolano a este aumento del aislamiento internacional y regional no ha sido la de tratar de recuperar su legitimidad y aumentar la participación democrática. Por el contrario, ha optado por más control estatal y partidista y por la profundización de sus tendencias autoritarias.

Los partidos de la derecha internacional, los principales medios globales de derecha (The Miami Herald, El Tiempo de Bogotá, El País de Madrid, CNN, Fox News, incluso periódicos supuestamente liberales como The New York Times y el Washington Post, o medios de comunicación «responsables», como la BBC, así como muchos gobiernos en todo el continente americano y la Unión Europea, han definido al gobierno venezolano prácticamente como enemigo público número uno, a veces compitiendo con Corea del Norte. Todos ellos pretenden hablar y actuar en nombre de la defensa de la democracia en Venezuela amenazada por un gobierno autoritario. Es indudable que el gobierno venezolano ha tomado un camino que lo aleja sustancialmente de la Constitución democrática de 1999 y de aspectos fundamentales del proyecto político original de Chávez, pero esto de modo alguno explica la histeria de la llamada comunidad internacional en torno a Venezuela. ¿Dónde estaban todos esos defensores de la democracia cuando la derecha brasileña derrocó al gobierno democráticamente elegido de Dilma Ruosseff? ¿Por qué no hay protestas en esta llamada "comunidad internacional» sobre el hecho de que en los últimos decenios, según la ONU, más de 30 mil personas han desaparecido en México. ${ }^{26}$ ¿Cuántos titulares periodísticos y sanciones se han producido como respuesta a la sistemática guerra asesina contra los usuarios de drogas por parte del gobierno de Rodrigo Duterte en Filipinas? ${ }^{27}$ ¿Por qué los gobiernos de los Estados Unidos, el Reino Unido y Espańa, tan preocupados por la democracia, tienen relaciones tan cordiales con el régimen saudita a pesar

25 José Silva, «MUD apoya las sanciones económicas de EEUU hacia Venezuela», El Universal, Caracas, 28 de agosto de 2017.

26 Sergio Ocampo Arista, "Podría haber más de 30 mil desaparecidos en México: ONU», La Jornada, México, 9 de agosto de 2017.

27 En su visita a las Filipinas en noviembre del 2017, Trump declaró que tenía una "gran relación» con Duterte. Oliver Holmes, «Trump hails 'great relationship' with Philippines' Duterte», The Guardian. Londres, 13 de noviembre 2017,

[https://www.theguardian.com/us-news/2017/nov/13/ trump-hails-great-relationship-with-philippines-duterte] 
de su carácter totalitario y sus continuados ataques genocidas contra la población de Yemen? ¿Serán los enormes y lucrativos negocios de armas parte de la explicación? ¿La geopolítica del petróleo? ¿Por qué estas preocupaciones por la democracia no parecen aplicarse a las autocracias del mundo árabe? ¿Se considera que el apartheid israelí es compatible con la democracia?

Venezuela ha sido construida como parte de un nuevo eje del mal (junto con Irán y Corea del Norte) por otras razones. El proceso bolivariano fue el más radical intento de trascender el capitalismo en el siglo XXI. Esta experiencia no solo tuvo gran impacto en el llamado giro a la izquierda que se produjo en la mayoría de los países de América del Sur. La experiencia venezolana se convirtió en una referencia, un rayo de esperanza, para gente tan lejos como Palestina, Filipinas y la India. Aunque el actual gobierno venezolano se ha alejado de estos imaginarios de una profunda transformación de la sociedad, a pesar de su corrupción y sus tendencias autoritarias, todavía es visto por muchos en la izquierda y movimientos sociales en todo el mundo como un símbolo o referencia subversiva. Desde la perspectiva de algunas elites globales estos imaginarios deben ser exterminados. Esto obviamente tiene poco que ver con preocupaciones en torno a la democracia. Esta auto-proclamada comunidad internacional está promoviendo un "cambio de régimen" en Venezuela, incluso si esto implica el riesgo de una guerra civil. Esto ha contribuido activamente a que una negociación interna para procesar las profundas divisiones existentes en la sociedad venezolana sea tan difícil.

La «amenaza autoritaria» representada por el gobierno de Maduro se ha convertido en un instrumento útil en las manos del gobierno conservador de Mariano Rajoy en Espańa para atacar a Podemos, por parte de los conservadores en el Reino Unido para poner en duda las credenciales democráticas de Jeremy Corbin, por Donald Trump, para mostrar a sus seguidores lo macho que es, y por la derecha mexicana en su intento de describir a Andrés Manuel López Obrador, quien encabeza las encuestas de opinión para las elecciones presidenciales del ańo próximo, como una radical amenaza chavista.

Venezuela, con las mayores reservas dehidrocarburos en el planeta y sus extraordinarios bienes minerales e hídricos, se ha convertido en un campo de batalla central de luchas inter-imperiales contemporáneas, tanto entre países, como entre corporaciones globales. Con el giro a la derecha y la geopolítica de re-alineamiento con los Estados Unidos de los gobiernos de Argentina y Brasil, Venezuela quedó aislada políticamente. Se mantiene como el principal territorio latinoamericano de las confrontaciones geopolíticas globales entre los Estados Unidos en defensa de su tradicional patio trasero, y la búsqueda por parte de China y Rusia por convertir al país en una cabeza de playa para sus proyectos globales en este continente.

Hoy, para las empresas transnacionales, el problema no es que un gobierno izquierdista o nacionalista limite su acceso a las abundantes fuentes de energía del país o sus riquezas minerales. El gobierno ha abierto el país a las inversiones extranjeras en petróleo y minería en condiciones sumamente favorables para estas empresas. Es el caso de la Faja Petrolífera y el Arco Minero del Orinoco. Dado que este tipo de inversión no es rentable en el corto plazo, muchas empresas transnacionales están esperando a tener más seguridad jurídica a fin de proceder con sus anunciadas inversiones. A pesar de que en el mega proyecto del arco Minero del Orinoco se han establecido condiciones extraordinariamente favorables para los inversores extranjeros, estas normas fueron aprobadas por decreto presidencial y constituyen una clara violación de la Constitución y normas jurídicas referidas al ambiente, a los pueblos indígenas y en el ámbito laboral. Estas normas y los nuevos contratos con empresas transnacionales no han sido aprobados por la Asamblea Nacional como lo exige la Constitución. No hay garantía de que vayan a ser reconocidos en el caso de un cambio de gobierno. Según muchos críticos de izquierda, esta es una de las principales razones por las que el gobierno de Maduro decidió convocar a una nueva Asamblea Constituyente: proporcionar el sólido marco jurídico y constitucional necesario para atraer estas inversiones. Una propuesta de ley con este propósito ha sido introducida por Maduro a la ANC. Es poco probable que estos esfuerzos tengan éxito, ya que en las condiciones actuales, la ANC no es vista como legítima ni por la mayoría de la población venezolana ni por la llamada «comunidad internacional».

Muchos intelectuales internacionalmente reconocidos, partidos y movimientos sociales identificados con la izquierda no están contribuyendo a la creación de las condiciones de una salida no violenta de la crisis actual. En el mismo marco de Guerra Fría que caracteriza la perspectiva dominante de la derecha, gran parte de la izquierda internacional 
continúa identificando al gobierno de Maduro como un gobierno democrático, popular y antiimperialista $y$ tienden a proporcionarle una solidaridad incondicional. Esto a pesar de las políticas ultra liberales de zonas económicas especiales para atraer las inversiones extranjeras; a pesar de la profundización del modelo extractivista depredador que ha dado origen a los mayores problemas que enfrenta el país; a pesar de su negativa a tratar con responsabilidad el cambio climático en su papel como importante productor de petróleo; a pesar de que durante el proceso bolivariano ha habido una consolidación de la inserción histórica del país en la división internacional colonial del trabajo y la naturaleza; a pesar del hecho de que los pueblos indígenas siguen siendo severamente impactados por las políticas neodesarrollista en sus territorios ancestrales; a pesar de las tendencias antidemocráticas, autoritarias y represivas que caracterizan hoy al gobierno de Maduro. Esta solidaridad incondicional, acrítica, contribuye a bloquear la posibilidad de análisis críticos de los problemas del proceso bolivariano y contribuye activamente a reforzar y legitimar sus rasgos más negativos. Las opiniones tienen consecuencias. Con independencia de las decisiones que tome el gobierno de Maduro, estas han sido celebradas por parte de sectores de la izquierda internacional como brillantes tácticas antiimperialistas. Como por arte de magia, las mismas políticas que se denuncian si son llevadas a cabo por gobiernos neoliberales o derechistas, de alguna manera se convierten en aceptables si son llevadas a cabo por gobiernos «progresistas» o de «izquierda». El extractivismo de la derecha es considerado como una política pro-imperial que tiene graves consecuencias ecológicas y socioeconómicas, como amenazas a las comunidades indígenas y campesinas y como una renuncia a la soberanía nacional en favor de las empresas transnacionales. Los movimientos de resistencia en estas condiciones son celebrados. Por otro lado, cuando esas mismas políticas son llevadas a cabo por gobiernos «amigos» de alguna manera pasan a tener un significado radicalmente diferente y los movimientos de resistencia son acusados de formar parte de una agenda imperial antinacional y antipopular. Con esta construcción maniquea de la realidad, no hay manera de aprender de la experiencia. Las razones para cada problema o error siempre se encuentran en otra parte.

Todo esto le hace un dańo enorme a los movimientos anticapitalistas y proyectos transformadores alrededor del mundo. Alimenta la propaganda derechista que define toda alternativa anticapitalista, por su propia naturaleza, como necesariamente estatista, autoritaria y corrupta. Parece que amplios sectores de la izquierda continúan teniendo grandes dificultades para extraer lecciones de las consecuencias a largo plazo que tuvo la incapacidad para criticar a la Unión Soviética, a pesar de su carácter autoritario y represivo, porque se enfrentaba al imperialismo estadounidense.

Venezuela es hoy un campo de batalla decisivo, no solo en el ámbito geopolítico del las competencias interimperiales. Es también un terreno privilegiado de la confrontación de ideas, en debates críticos sobre cómo avanzar en la dirección de una sociedad democrática postcapitalista que supere el patriarcado, el antropocentrismo y el racismo, así como el estado de guerra permanente que caracterizan al sistema mundo contemporáneo. Un debate reflexivo, crítico, del proceso político venezolano es indispensable si esta experiencia ha de contribuir a la construcción de otro mundo posible. 